\title{
EDITORIAL
}

\section{Severe pulmonary hypertension: walking through new paths to revisit an old field}

\author{
A.T. Dinh-Xuan*, M. Humbert", R. Naeije
}

\begin{abstract}
Almost 10 yrs ago, a series of manuscripts on pulmonary hypertension appeared in the European Respiratory Journal [1-9]. These in-depth reviews caused a great deal of interest in the readers as they covered various aspects of this unique condition, which causes hypertension in a region of the body in which the artery blood pressure should always remain low, as opposed to its systemic counterpart. Almost 10 yrs later, exciting new stories about the origin, mechanisms, identification and cure of this pulmonary disorder have slowly emerged that are certainly worth telling now.
\end{abstract}

One of the most dramatic breakthroughs was the recent discovery of the role played by bone morphogenetic protein receptor type II (BMPR-II) gene in the pathophysiology of familial pulmonary hypertension $[10,11]$. This led to a revival of interest in the use of genetic studies to dissect mechanisms and pathways leading to pulmonary vascular disease [12]. However, it soon became clear that the discovery of genes involved in disease would be of little help if the signalling pathways that are perturbed as a result of gene mutation could not be delineated. Following the same pattern, another recent breakthrough, which will certainly shed new light on understanding of pulmonary vascular physiology, was the discovery that the serotonin transporter (5-HTT) could play a pivotal role in the mechanisms leading to pulmonary vascular remodelling and severe pulmonary hypertension [13]. The crosstalk between 5-HTT and BMPR-II signalling pathways is yet to be clearly defined [14]. Nevertheless, it is probable that these factors are not alone as other crucial players like gelatinase [15] or endothelin [16] are also likely to be involved in this complex and intricate biological puzzle.

Although understanding the cause of severe pulmonary hypertension is crucial, it is certainly not the ultimate target. The main concern remains how to detect the disease in its early development and how to cure patients of this dreadful condition. Fortunately, progress has been made on all fronts of this unique

\footnotetext{
*Service de Physiologie-Explorations Fonctionnelles, Centre Hospitalier Universitaire Cochin, Assistance Publique-Hôpitaux de Paris, Université Paris V, Paris, France, " Service de Pneumologie, Hôpital Antoine Béclère, Clamart, France, and "Dépt des Soins Intensifs, Hôpital Universitaire Erasme, Brussels, Belgium.

Correspondence: A.T. Dinh-Xuan, Service de PhysiologieExplorations Fonctionnelles, Hôpital Cochin, 27, rue du faubourg Saint-Jacques, 75679 Paris cedex 14, France. Fax: 33158412345. E-mail: anh-tuan.dinh-xuan@cch.ap-hop-paris.fr
}

battle, ranging from noninvasive evaluation of pulmonary arterial pressure [17] to medical treatment and surgical procedures.

In this issue of the European Respiratory Journal, a new series of 12 reviews, written by those who are at the forefront of biological and clinical research in pulmonary hypertension, will begin with an article by Humbert and TREMBATH [18]. The present authors hope that this series will be more than simply a sequel to the first series of manuscripts published $10 \mathrm{yrs}$ ago, and are confident that these short reviews will provide insights and generate new ideas for readers when revisiting familiar fields of knowledge through recently discovered paths. Hopefully, this can be as interesting as rereading a favourite old book; re-examining the once overlooked pages and their obscure messages that become all at once obvious in the spotlight of new discoveries.

\section{References}

1. Higenbottam TW, Rodriguez-Roisin R. Highlights on pulmonary hypertension: a commentary. Eur Respir $J$ 1993; 6: 932-933.

2. Higenbottam TW, Cremona G. Acute and chronic hypoxic pulmonary hypertension. Eur Respir J 1993; 6: 1207-1212.

3. Agustí AGN, Rodriguez-Roisin R. Effect of pulmonary hypertension on gas exchange. Eur Respir J 1993; 6: 1371-1377.

4. Naeije R. Medical treatment of pulmonary hypertension in acute lung disease. Eur Respir J 1993; 6: $1521-1528$.

5. Weitzenblum E, Kessler R, Oswald M, Fraisse P. Medical treatment of pulmonary hypertension in chronic lung disease. Eur Respir J 1994; 7: 148-152.

6. Voelkel NF, Tuder RM. Cellular and molecular mechanisms in the pathogenesis of severe pulmonary hypertension. Eur Respir J 1995; 8: 2129-2138.

7. Chaouat A, Weitzenblum E, Higenbottam TW. The role of thrombosis in severe pulmonary hypertension. Eur Respir J 1996; 9: 356-363.

8. Kessler R, Chaouat A, Weitzenblum E, et al. Pulmonary hypertension in the obstructive sleep apnoea syndrome: prevalence, causes and therapeutic consequences. Eur Respir J 1996; 9: 787-794.

9. Kneussl MP, Lang IM, Brenot FP. Medical management of primary pulmonary hypertension. Eur Respir $J$ 1996; 9: 2401-2409.

10. Deng Z, Morse JH, Slager SL, et al. Familial primary 
pulmonary hypertension (gene PPH1) is caused by mutations in the bone morphogenetic protein receptorII gene. Am J Hum Genet 2000; 67: 737-744.

11. Lane $\mathrm{KB}$, Machado $\mathrm{RD}$, Pauciulo $\mathrm{MW}$, et al. Heterozygous germline mutations in BMPR2, encoding a TGF- $\beta$ receptor, cause familial primary pulmonary hypertension. Nat Genet 2000; 26: 81-84.

12. Newman JH, Wheeler L, Lane KB, et al. Mutation in the gene for bone morphogenetic protein receptor II as a cause of primary pulmonary hypertension in a large kindred. N Engl J Med 2001; 345: 319-324.

13. Eddahibi S, Humbert M, Fadel E, et al. Serotonin transporter overexpression is responsible for pulmonary artery smooth muscle hyperplasia in primary pulmonary hypertension. J Clin Invest 2001; 108: 1141-1150.

14. Rabinovitch M. Linking a serotonin transporter polymorphism to vascular smooth muscle proliferation in patients with primary pulmonary hypertension. $J$ Clin Invest 2001; 108: 1109-1111.

15. Frisdal E, Gest V, Vieillard-Baron A, et al. Gelatinase expression in pulmonary arteries during experimental pulmonary hypertension. Eur Respir J 2001; 18: 838845.

16. Takahashi H, Soma S, Muramatsu M, Oka M, Ienaga H, Fukuchi Y. Discrepant distribution of big endothelin (ET)-1 and ET receptors in the pulmonary artery. Eur Respir J 2001; 18: 5-14.

17. Naeije R, Torbicki A. More on the noninvasive diagnosis of pulmonary hypertension: Doppler echocardiography revisited. Eur Respir J 1995; 8: 14451449.

18. Humbert M, Trembath RC. Genetics of pulmonary hypertension: from bench to bedside. Eur Respir $J$ 2002; 20: 741-749. 